\title{
LITERATURE FOR 1911 ON THE BEHAVIOR OF VERTEBRATES
}

\author{
JOHN B. WATSON \\ Johns Hopkins University
}

\section{VISION}

Fish. C. Hess (I 3 ) offers a new piece of apparatus for the study of adaptation in fish. At one end of a dead black tunnel three metres in length he places a five candle power electric light with frosted bulb. At the opposite end of the tunnel and inclined at an angle of 45 degrees to its axis he places a diffusing surface of ground glass. The light from this surface is reflected out to a dish which contains the fish. Large changes in intensity are made by substituting lamps of higher or lower candle power, while fine gradations are obtained by the use of the rotating sector and by moving the lamp. The animals are light-adapted in the sun and then quickly placed in the experimental tank. The animals respond by swimming towards the side of the tank receiving the rays from the ground glass as soon as the process of adaptation is sufficiently advanced. For example, the carp exposed to the rays of the sun for one-quarter of an hour, show in the first second of time no tendency to swim towards the light when the 5 c.p. light is $30 \mathrm{~cm}$. from the ground glass. After 20-30 seconds in the dark room, they swim toward the lighted side when the lamp is moved back I-2 metres. After 10-I 5 minutes adaptation, they swim towards the light when the lamp is 3 metres distant from the screen and the rotating sector set with a 30 degree opening. He concludes that light sensitivity is increased over a thousand fold after fifteen minutes of adaptation. In some cases even a greater increase in sensitivity is found.

He finds an essential difference between the human and the fish eye. In man the retinal pigment even in long exposure to light does not essentially change its position, while in the case of the fish the pigment upon light exposure wanders soon toward the vitreous humor. This may offer a physical expla - 
nation for a small part of the process of adaptation, but Hess maintains that the process as a whole is physiological.

The forward migration of the pigment in light exposure alters the general effect of the light. The advanced pigment absorbs relatively more of the short wave-lengths than of the long. In order to obtain a relation of equality (for the fish) between given red and blue lights one must use a blue 4-8 times as intense for the eye with pigment advanced as that used for the eye with the pigment retracted. The pigment absorbs little of the green rays This is shown by the fact that the fish which collect in the brightest part of the container seek the yellow-green both when the pigment is in the forward position and in the retracted.

The physiological changes in light (monochromatic) intensity incident upon the migration of the pigment might easily be confused with the Purkinje phenomenon, as was done by Bauer. Hess still emphatically denies that there is any such phenomenon present, and reaffirms his old conclusion that the fish are color blind. It is interesting to note that he everywhere emphasizes the low stimulating value of red.

Bawer (I) in an extended reply to Hess (see this journal, Vol. I, p. 432, for review of Hess' criticism) reasserts his conclusions that the fish in the light-adapted state are strongly stimulated and even terrified by red (rotscheu) and that they behave as though the Purkinje phenomenon were present. In the last paper just reviewed Hess (p. 4ro) says that Bauer's results are due to error, and that on repeating the experiments upon Atherina he finds that the animals do not avoid the red either in the light-adapted state nor in the dark-adapted state. If this is true, and Hess' work is everywhere consistent, the bottom of the quarrel drops out. Bauer's contention that the fish when light-adapted are normal in color vision and when dark-adapted are color-blind is absurd upon its face. His only real support of so strange a position lies in the asserted fact that the light adapted fish are "red-shy"-i.e., that in addition to its brightness value red has a peculiar shock effect. Furthermore, from Hess' work on pigment migration we might very well expect a difference between the light-adapted and the dark-adapted fish in their responses to red and blue-green. This it would seem does away effectually with Bauer's claim for a Purkinje effect. The point is more important than would appear at first sight. 
The Purkinje effect is absent in the totally color-blind, and if the fish are totally color-blind as Hess maintains, one could not explain a true Purkinje effect.

Reptilcs and Amphibians. Experiments by Casteel (5) on the turtle (Chrysemys marginata) bring out the fact that the animals failed to discriminate between patterns. Four animals learned to discriminate between black and white, while one failed to show improrement in 220 trials. Two learned to discriminate vertical and horizontal lines and two between two series of parallel horizontal lines $8 \mathrm{~mm}$. and $2 \mathrm{~mm}$. in width respectively. One turtle learned to discriminate between two series of parallel vertical lines $8 \mathrm{~mm}$. and $\mathrm{I} \mathrm{mm}$. wide and then between lines 4 $\mathrm{mm}$. and $2 \mathrm{~mm}$. wide and finally between lines $3 \mathrm{~mm}$. and 2 $\mathrm{mm}$. wide. Although not carefully tested, the retention of such habits was surprisingly good.

Casteel states that the turtle does not learn rapidly. One hundred and eighty-three trials were the average necessary to complete the above habits. From extended experiments (Hopkins) in which monkeys, dogs, rabbits and rats have been used as subjects in discrimination experiments it would appear that the turtle learns rather rapidly. It is not at all unusual for the above animals to require $200-600$ trials to perfect similar discriminations.

Victor Bauer (2) defends the view that the risual purple functions in daylight rision as well as in brilight vision. His experiments were carried out upon frogs and rabbits. The retinae of these animals were exposed to light for varying periods under varying conditions, and the color of the retina was then determined. From his results he finds support for the following general conclusions. When the risual purple is bleached by the action of light, certain products are split off. Some of these products enter into reaction with the nerve substances and stimulate them, while others act upon the secretory epithelium surrounding the retina. The secretions resulting repair or reconstruct the bleached-out purple. The waste and repair of the risual purple takes place not only in dim twilight but even in strong daylight. This may be shown in the isolated bulb, in which the "Restitutionskraft" of the secretory epithelium is gradually exhausted by removal from the body. If sudden strong illumination is admitted to the eye which has been pre- 
viously kept in the dark there is a corresponding rich formation of the bleaching products. The building up process is at first not able to repair the waste. Adaptation follows, and the building up process not only compensates for the waste, but continues until the retina which was bleached under the infuence of the strong light again becomes red. There is an upper limit to the speed of the restitution process. If the decomposition is increased overwhelmingly, even the greatest activity on the part of the epithelium fails to restore equilibrium, and the retina remains bleached out. Only a decrease in illumination can restore the purple. After a more complete adaptation the "purpling" processes continue, but with lessened activity. In continued darkness the regeneration processes cease, probably in consequence of the lack of the by-products necessary for their arousal.

Birds. Hess (13) (p. 443) confirms by a new method his former conclusion that light-adapted day birds have an extension in the red end of the spectrum coincident with man's, but that the blue-greens, blues and violets have low stimulating value. The explanation of this is to be found in the reddishyellow oil globules which are to be found in the retina of birds. These absorb the short but admit the long rays. It will be remembered that he in his earlier paper maintained the view that the hen has visual qualities similar to those of the human being, but that due to the presence of the oil globules there are certain differences in behavior. All these differences between hen, and man with normal vision, are smaller than between the hen and the totally color-blind or red-green blind man. I quote his own words (p. 445) on the coloring of the rice kernels for tests on the color blindness of the hen. I am in some doubt as to his meaning, or if I get his meaning, of the possibility of obtaining any such color equations: "Um Huhner nach dem Prinzip der Seebeck-Holmgren'schen Wollprobe mit farbigem Futter zu untersuchen, farbte ich grossere Mengen von Reiskornern mit rerschiedenen Pigmenten so, dass mir insbesondere gelblichrote, angenahert rein rote und blaulichrote, sowie gelblichgrune, angenahert rein grune und blaulichgrune Korner teils in schon freien, teils in mehr oder weniger stark mit Weiss, Grau oder Schwarz verhullten Farben, ferner gelblichgraue, rein 
grane und blaulichgraue Korner reichlich zur Verfugung standen." (P. 445.)

Upon a dead-black table cloth 15 by $39 \mathrm{~cm}$. in diameter he lightly fastened yellow-red grains and between these strewed the different greens and greys. On the second day the hen avoided not only the yellow-red grains, but also the red grains and the bluish red, and pecked only at the greys and greens. This was also the case when he strewed red grains among the greens and the greys (although in this case the red grains were no longer fastened down). With astounding quickness and sureness the animal pecked all the green and grey grains lying between the red grains. If there were only a few of these at hand, it hunted all over the entire cloth between the red grains so that after several seconds only the red ones remained untouched. If he brought such a hen into the dark room to a row of white rice grains, strewed upon a black background, which were not fastened down, and colored these by means of the spectrum, she here likewise left the red and yellow-red grains untouched.

He now laid before a so-called red-green blind person (relatively yellow sighted red-green blind) the differently colored yellow-red and blue-red rice grains and let him choose out of the pile the grains which seemed alike to him. This subject put yellow-green with yellow-red, "pale blue with bluish-red. The differently colored grains which the hen had differentiated with such sureness were similar or alike to the red-green blind subject.

A hen which he had taught to aroid the red grains was fed on a black cloth upon which the green grains were fastened down while the red, etc., were scattered loosely. After a short time she no longer took the green grains when these were loosely strewn among the others, but she did take the red ones. In the spectrum she picked the grains lying in the red end as far as they were visible to the normal human eye.

Only for one with the visual qualities of the normal human eye have the different red grains the common characteristic of prevailing redness. He concludes that the possibility of a redgreen blindness in the hens experimented upon is excluded, and greater strength is given to his contention that their visual qualities in this respect are similar to or the same as a normal man's. 
Breed's (4) paper is concerned more with the modifiability of reactions than with the function of vision as such. Nevertheless experiments were made upon the color, form and size perception of the chick. The evidence for color rision, while obtained incidentally, is believed by the author to support the view that color quality as well as intensity is a determining factor in the chick's response. The chicks seem to be able to respond selectively to one of two objects of different size. The form tests gave purely negative results. In a note on page 57 the author states, however, that a chick acquired the circlesquare habit when the experiments were conducted in the dark room. One interesting methodological point is brought out in Breed's work. Chicks will peck in the dark. The work of Hess and of Katz and Révész on vision in the chick is based upon the assumption that the chick will not peck at what it cannot see. The work which the reviewer has carried out upon the limits of the spectrum in chicks this summer wholly confirms Breed's findings in this respect.

Mammals. Minkowski ( ${ }_{7}$ ) reports in a long and closely articulated paper the results of extended tests upon the localization of the risual centers in the dog. The methods of testing the visual field in normal dogs and of locating the visual defects in the dogs after cortical operation are described as follows. The dog sat with one eye securely bandaged. A piece of meat was then held by a slender rod or with forceps before the other eye at a distance of about $10 \mathrm{~cm}$. This gave a reasonably steady fixation. A perimeter was then drawn forward in such a position that the bit of food occupied its center. A second bit of food was then drawn along one arm of the perimeter until the dog noticed the food and snapped at it. By rotating the perimeter in the usual way the following field was mapped out:

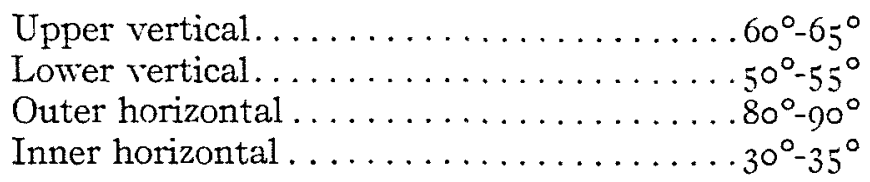

The "Kreisführungsmethode" was employed in a supplementary way. This consisted in moring the bit of food before both eyes of the dog in circles so that the image had to fall at some time upon the upper, lower, inner and outer portions of the retina. 
The normal dog follows the food in all directions with pronounced movements of the eyes and muzzle. But where there are marked deficiencies in rision, as in the lower half of the campus oculi sinistri, the definite following movements suddenly cease, but begin again when the food is brought within the risual field. At the moment of disappearance, seeking morements of the eyes and muzzle may be noticed. This method gires quick orientation where the deficiencies brought about by cortical extirpation are great. The third auxiliary method he calls the "Auseinanderfuhrungsmethode." Two bits of food are first held above the dog's nose and are then drawn apart in all directions; sometimes both are drawn apart simultaneously, while at others one remains fixed and the other is moved away. (At least so I understand "-dass zwei Nahrungsstucke zuerst uber der Nase gehalten und dann verschiedenen Richtungen einzeln oder gleichzeitig auseinander gefuhrt werden").

For the results of the experiments on extirpation of the cortical areas and for the anatomical findings the original paper must be consulted.

\section{AUDITION}

Fish. Parker (20) finds that the noise of motor boats is extremely faint under water and has almost no influence upon the movements of fishes engaged in feeding. Single explosive sounds like that of the report of a gun are likely to startle the fish and catise a temporary cessation of feeding.

Some tests made by Dr. A. G. Mayer, Dr. Goldfarb and the reviewer in Tortugas during the past summer on the distance at which sounds produced under water may be detected by a person with head and body immersed do not bear out Parker's contention that sounds heard under water are extremely faint. Dr. Mayer tapped two pieces of coral together under water while Dr. Goldfarb and the reviewer swam away. Up to a distance of approximately roo yards the faint sound made in the above manner was distinctly heard by both observers with head and body immersed. At this distance Dr. Mayer tapped the two pieces of coral together in the air. They were clearly audible to the observers with heads in the air, but unfortunately we did not try the experiment of giving the sound in the air with the observers' heads immersed.

In Parker's work no mention is made of the possibility of 
rision being responsible even for the slight responses he obtained. In the opening sentences of the present paper he says that the fish can feel sounds through the skin, lateral line organs and through the ears proper. One of the strong criticisms urged against all of Parker's auditory work by certain German reviewers is that he does not exclude the possibility of response through vision (i.e., visual response to actual wave motions produced by the sounding body). In the present paper, although he cites the work of Hunter ( 1782 ) on the responses of fishes to the noise produced by the discharge of fowling pieces, he does not consider the work of Bernoulli (Zur Frage des Horvermogens der Fische, Arch. f. d. ges. Physiol., 134, 633-644. See review of r 910 literature in this journal, Vol. I, p. 436), who made similar experiments and arrived at similar conclusions.

Mammals. Shepherd (24) finds that the raccoon learns to respond to its own name and to other articulate sounds. Confusion words were not reacted to. Variations in the pitch of the voice and in the timbre of the roice did not cause failure to discriminate. This work seems to the reviewer merely indicative; in no sense can we say on the basis of such tests that Shepherd's conclusion is justified. The simplest and most fundamental precaution was neglected,-that of being out of sight of the animal during the experiments

\section{OLFACTION}

Fish. Parker (I g) tested the ability of Fundulus to discriminate between packets of cotton cloth containing dogfish meat and others not containing food. The packets without meat were occasionally approached and seized, but soon dropped. The killifish, in contrast with the catfish, used its eyes as well as its chemical senses in seeking food.

The olfactory nerves were then cut in several animals. Twentyfour hours after the operation the fish were fully active and took food. When tested with the food packets they nibbled at both in a way that made it impossible for the uninformed observer to distinguish one packet from the other. Since the operation of cutting the olfactory nerves was somewhat severe, Parker tested the effect of closing the anterior olfactory apertures by stitches of fine silk. Again discrimination between the 
packets was lost. It was restored when the stitches were removed. In cases where the stitches were taken, but where the threads were not drawn up and tied so as to close the aperture, discrimination was not lost. Parker concludes that Fundulus heteroclitus uses its olfactory apparatus as an organ with which to scent its food; "i.e., its olfactory apparatus is a chemical distance-receptor of rery considerable importance in its daily activities." 1

Sheldon's (23) work on Selachians is in harmony with that of Parker. When a crab is placed in a pool containing dogfish a few minutes are necessary for diffusion to take place The dogfish which first happens to swim within three or four feet of the crab turns suddenly as if startled, and swims about now eagerly alert and searches for the food. When within three or four inches of the crab it suddenly scizes it and makes off rapidly. Very little use of vision is noted. The food packet method was tried with convincing results. Packets containing stones were not touched, while those containing crabs were always seized. Packets saturated with the juice of a crab and weighted with a stone were likewise seized. When the nasal passages are closed with cotton wadding coated with vaseline, the fish do not respond to the food stimulus. The radding produces some disturbance, but this factor was sufficiently controlled by testing fish with one aperture closed. From one to two days after the removal of the plugs fish so treated responded normally again.

The general conclusion is that Selachians find their food almost exclusively by a sense of smell which is comparable to that possessed by terrestrial vertebrates.

Birds. Strong (26) takes up the rexed problem of smell in birds from the standpoint of both morphology and behavior. His study of the anatomical features of the olfactory organs in birds leads him to agree with Edinger, wiz., that one ought to expect to find evidence of a sense of smell. There is a great variation in the size of the olfactory structures in the different

\footnotetext{
${ }^{1}$ Since neither Parker nor Sheldon mentions the previous work of Baglioni (Baghoni, S., Contributions expérimentales à la physiologie du sens olfactif et du sens tactile des animaux marins., Archiv. Ital de Biol., 1909, 52, 225-230), I cannot help calling attention to the fact that this investigator, on the basis of tests upon the octopus and blind fish (Balistes), urges that these marine forms possess such a chemical sense, and on the question as to whether it should be called smell or taste comes out strongly in favor of calling it smell, since from the standpoint of reaction it is a distance-receptor.
} 
species. Certain of the birds (Dromaeus and Fulmarus) have relatively larger olfactory apparatus than man. There is some eridence (according to his interpretation) in the case of the higher birds that the development of keen rision is being accompanied by a degeneration of the olfactory sense. On pp. 642 and 643 one finds a table of comparative measurements of the different parts of the olfactory structure, and on 659 and $66 \mathrm{I}$ excellent drawings of the olfactory organs and of their external relations to the brain as a whole.

On the behatior side, Strong presents some results obtained from experiments upon a maze which offered the possibility of association between a given odor and food. The birds never learned to find their food with perfect accuracy during a series of tests given twice daily and extending over a period of nine months. During this time, however, there was an increase in the number of correct responses to the oil of bergamot. Strong's field observations upon the turkey rulture in Florida were not productive of convincing results.

No control experiments upon birds with olfactory bulbs removed were made. It seems probable that Strong's tests could have been carried out much more quickly and easily if the two "choice" method instead of the four had been followed.

\section{EXPERIMENTAL AND OBSERVATIONAL STUDY OF INSTINCTS}

Fish. Sumner $(27)$ in a rather loosely articulated paper gives the results of his highly interesting experiments upon the adjustment of the flatfish to its background. Pages 467 $47 \mathrm{I}$ give a very clear summary. In brief, Sumner finds that flounders become very pale upon white backgrounds and very dark upon black ones. These adaptive changes usually lie within the black-white series. In mixed backgrounds composed of sand and gravel the fish respond by assuming definite patterns oftentimes in distinct harmony with those of the background. Backgrounds made up of areas of black and white call forth greater contrasts in the skin patterns than those of sand and gravel. Squares, crossbands, circles, etc., were never copied in any true sense. Adaptation is most complete upon backgrounds forming a part of the natural habitat of the animal, but it is not limited to such conditions. There is a wide range of adaptability. 
The markings of the underlying surface were most effective in calling forth the changes. The markings on the rertical walls of the tank although effective were less important, while the overhead environment exerted little or no influence."

The fish seems to make no direct comparison between its body and the background. Adaptive changes occur when the fish is buried in the sand and when its body (eyes excepted) is covered with a cloth.

The changes in some way are conditioned upon optical processes, since at least one eye must fuction normally if the changes are to occur. If blinded when in the dark condition, the fish ordinarily remained dark; if blinded in the pale condition, they remained in that state for about a day and then reverted to a darker condition.

The author is conservative in his statements throughout and rests content largely with stating his findings. The photographs are excellent and on the whole convincing. The reviewer feels that the patterns shown in the photographs could have been somewhat better evaluated if Sumner had photographed along with the flatfish some fish rather constant in its color tone and pattern, and one which does not undergo such adaptive changes. In many cases, though, the author has photographed the flatfish in pairs in such a way as to leave no room for questioning the pronounced effect upon the pattern of the fish of changes in the backgrounds.

Werner (28) calls attention to the sleeping attitudes of several species of fishes (Amiurus nebulosus, Misgurnus fossilis and Cobitus talnia). Sleep is needed hy all members of the groups particularly studied (Silurus glanis and Cobitus barbatula) but the bodily attitudes taken are quite different even in the nearly related races. In general there is a complete cessation of activity, a certain chosen bodily attitude, and almost complete stoppage of breathing. Very light contact is sufficient to reawaken the fish.

Romeis (2I) takes up in detail the peculiar movements of the Maulbruter (Paratilapia multicolor) in seeking during the breeding season a resting place under the leaves of certain water plants. When in the neighborhood of the thickly matted plant leaves, it interrupts for some seconds the lively play of its fins, swims slowly here and there, and when a suitable place 
is found it folds its fins, assumes a characteristic position (ganz schrag auf seine Breitseite gelagert) and remains in this attitude from one-half to two hours. Only the regular but slow movements of the gill cover show that life is present. Romeis doubts whether the above described form of sleep is very profound, since the near approach of any object, or noises, causes the fish to take fight immediately. The author sees in this activity a mechanism which is economical with respect to metabolism. It should be designated generally by "Ausruhstellung."

At night the behavior is different, the fish ordinarily sinks to the hottom of the container and rests on the ventral surface. Fin morements cease. It seems to be genuinely asleep, since light in moderate intensities and noises do not disturb it.

Amphibians. Mulder (I8) finds that the speed of the rotation reflex is directly proportional to the amount of the stimulus. The relation is not logarithmic as is the case nith sensations.

Birds. Breed (4) finds that the drinking instinct does not have to be supplemented by imitation, accident, intelligence, instruction, etc., in order to act. The pecking response as a whole is very imperfect at birth. For purposes of observation the response is subdicided into three separate reactions: striking, seizing and swallowing. The amount of daily improvement of the act as a whole and of its separate parts was measured up to the $25^{\text {th }}$ day. Pecking improved in accuracy rapidly during the first two days. On the third day efficiency is placed at 29.29 on a scale of $50,40.10$ on the elerenth day and never higher than 42.57 for the rest of the time of observation. Social influence exerted little effect in improving accuracy.

On page 40 Breed raises the very interesting question of the relation of habit to instinct. Although in pecking there is improvement with practice, the question remains whether the increase in accuracy is dependent upon practice, or whether it is the natural functional correlate of structural maturation. The question might be answered experimentally, it would appear, by forced feeding of a group of chicks for the first week and then making a comparison of the accuracy of pecking with that of a group brought up in the normal way. Since the nervous system resists starvation well, it is doubtful if a few days of slight underfeeding would check the normal rate of the development of the sensory-motor arcs. 
Craig (Io) shows that stimulation of a female dove by the male without copulation was followed by oriposition. "The present paper goes to show that the stimulus to the whole process of egg development and laying is a psychic (neural) stimulus not dependent upon the introduction of sperm." (P. 305.)

Chappellier's (6) paper is a brief report upon a systematic study of the sex organs and sex life of hybrid birds. He discusses the apparent sex indifference in female hybrids obtained from crossing canaries and goldfinches. He mated one of these females with a canary. Nest-building began shortly after mating. The process of nest construction was desultory and lasted through the egg-laying period. The first egg was laid more than two months after mating. During 92 days she laid 16 eggs in a very irregular fashion and ate each of them in turn within one or two days after laying it. Although mated with an ardent male, she was entirely indifferent to him. This passivity in hybrid females is connected with a rudimentary condition of the oraries, which are represented by three or four small formless masses.

Herrick (12) derotes nearly roo pages to the nest structures and the activity of nest-building in birds. The series of papers is very comprehensive. He treats of the function of the nest, the classification of nests on the basis of behavior, analysis of increment nests, rariations in nests of certain birds, nidification, intelligence in nest-building and the origin of the instincts of incubation and nidification. The discussion of nidification is based chiefly upon the writer's field observations of behavior in nest-building. The author is conservative in his discussion of the presence of intelligence in nest-building: "Instinct furnishes the springs of action in birds." These are exceedingly complex and in a high degree adaptable. This innate equipment takes the place in a large measure of mind or intelligence. He finds evidence of a wide group of associations between sense impressions and motor impulses. Habits of approaching and learing the nest are quickly formed. Apparently one finds occasional adjustment of means to end where difficulties arise.

In regard to the origin of instincts of incubation and nidification, Herrick reaffirms his former position: the instinct to hide supplemented by that of guarding the eggs is responsible for the later instinct of incubation where guarding with concealment 
is effected in the same act. Why the instinct of incubation needs to have its "origin" accounted for any more than that of the hundred other instincts birds possess is not clear.

Craig $(8,9)$ gives the best description we have of the intimate family life of the mourning dove. He describes the various emotional states of the birds, such as those expressive of enmity, fear, alarm, and gives their various calls and cries in musical notation. The second part of the first paper (The Expressional Life History) treats of the breeding habits of the mourning dove. The breeding cycle of a pair of captive birds taken from Professor Whitman's aviary is described in detail.

His opportunity for making original observations upon the passenger pigeon was more limited. The species is now apparently extinct, and for this reason his rather brief notes upon the life history of Ectopistes are of especial interest. This species possessed characteristic voice, gesture and social life. It was comparatively awkward upon the ground and was therefore naturally less given to strutting and charging than other pigeons. Its voice was strident and lacking in musical notes. While the bird was quarrelsome, it was poorly equipped for fighting. Its courting was characterized by great roughness.

\section{ORIENTATION}

Mammals. V. Máday (I6) discusses the problem of orienlation in the horse. The origin of the impulse to home in this animal is supposed by the author to have been carried over from its wild ancestors. The Heimweh of the domestic horse has its origin in the Wandertrieb of its wild progenitors. This Heimweh is probably the most compelling impulse possessed by the horse.

Tests of homing were made by riding to distant points and then releasing the reins, thus allowing the horse to return by its own unaided efforts. The author tells us that he did not direct the horse except when gross errors were made! Surely the involuntary attitudes of the rider may have played a part both in the successes and the failures of the animal! When the horse reached the designated spot he was given the reins. The animal remained still for from one to two minutes, then started forward, then turned in the arc of a circle $10-15 \mathrm{~m}$. in diameter and for a short distance retraced the outgoing course, 
finally choosing its own course so as to eliminate the detours made on the journey out. The journey was not made without error. Improvement by practice was noted. We are not given the details of the journeys-i.e., distance traversed, times on successive trips, etc., nor the prerious training of the horse. Several pages are devoted to discussion of theories, the senses of the horse, and the author's conclusions. In brief the latter are as follows.

Orientation is not a physiological reflex but a psychical process. All the senses play a rôle with the exception of taste. In the order of their importance in orientation the senses are listed as follows: smell, hearing, touch and sight. Direction, intensity and temperature of winds are important factors. It is curious that sight appears last in the list. He gives no experimental grounding for this particular hierarchy of the senses. From the author's note it appears that mistakes are often made when orientation is attempted through sight. In all of the higher animals orientation is a complex process involving both conscious and unconscious factors. The unconscious factor in orientation according to the author consists chiefly in a Richtungsgefuhl. His discussion at this point is so naive and out of place in a journal with the standing of the Zeitschrift für angewandte Psychologie that the reviewer feels compelled to quote it in full: "Welcher Art is die bei der Orientierung geleistete unbewusste psychische Arbeit? Antwort: sie besteht hauptsächlich in dem sog. Richtungsgef uhle.

Welche physiologischen Faktoren (Sinnesorgane) dienen dem. Richtungsgefühle zur Unterlage und welcher Art sind die dabei entstehenden Empfindungen und Vorstellungen? Antwort: von verschiedenen Organen (hauptsächlich dem Ohrlabyrinth) kommen Lageempfindungen; auf diesen baut die Seele ihre Raumvorstellungen auf." (P. 85). In concrete cases, according to V. Máday, this Richtungsgefuhl comes about through the unconscious registration' of "detours" (Darwin). It is evident that the author was not really prepared, either from the standpoint of his familiarity with psychological theory or from his experimental equipment, to undertake such a problem. It is to be regretted that the journal in which the article appears will continue to give space to the reports of such unsatisfactory experimental work and to such long and rambling discussions 
as are to be found in this article and in the one by Franken, on the instincts and intelligence of the dog, reviewed last year in the Journal of Animal Behavior.

\section{IMITATION}

Mammals. Shepherd (25) gives some experiments upon imitation in raccoons. One of the animals had learned by the trial and error method to walk up an inclined plane of poultry netting $\mathrm{r} .5 \mathrm{~m}$. in length and $25 \mathrm{~cm}$. wide to a box where food could be obtained. This animal was used as the "imitatee." Three other animals tested separately were allowed to watch the imitatee perform this feat. Since these animals repeatedly failed to profit by watching the trained animal perform the act, Shepherd concludes that "inferential" imitation does not form a part of the raccoon's mental equipment.

\section{HABIT FORMATION}

Amphibians. Schaeffer (22) finds that the three species of frogs studied ( $R$. clamata, $R$. sylvatica, $R$. virescens) learned to avoid disagreeable objects, such as hairy caterpillars, in from four to seven trials. These habits persisted for at least ten days. Under the influence of punishment by the electric shock, $R$. clamata learned to avoid earthworms treated with chemicals in two trials.

Those habits which are intimately connected with obtaining food are acquired by these animals in a time which is directly comparable with the acquisition of similar habits in higher forms, e.g., chick, tern, monkey, etc. The frog has been placed low in the scale of intelligence by other investigators. This is due to the fact that the problems presented it hitherto have called into play relatively few of its hereditary mechanisms. Two or three pages are devoted to the fruitless task of discussing the psychic processes in the frog.

Birds. Hunter ( $\mathrm{I}_{5}$ ) finds that the pigeon forms maze habits as readily as other birds, but not so readily as the rat and the squirrel. The maze habits are perfectly retained for four weeks. Visual and kinaesthetic cues are used in the learning process. Kinaesthesis does not play so important a rôle in the mental life of the pigeon as in that of the rodents. Although no especial tests were made upon audition, Hunter is in agreement with 
Rouse that pigeons are very sensitive to sounds. From the tests with the rotated maze Hunter draws the conclusion that pigeons seem capable of changing their system of cues in response to the varying demands of a new situation. It is unfortunate that Hunter could not carry out these rotation experiments in an apparatus which permitted of the simultaneous rotation of the background.

Cole (7) continued the work of Yerkes and Dodson on the relation of the strength of the stimulus (punishment by electric shock) to rapidity of habit formation when the discrimination is (1) easy, (2) medium, (3) difficult. Chicks (barred Plymouth Rocks) were used as the subjects. The relative brightness of the stimulus plates in the three sets of tests is given as follows:

(1) Easy discrimination.............. 8.9

(2) Medium " $\quad \ldots \ldots \ldots \ldots \ldots \ldots \ldots: 1, \ldots \ldots \ldots$

(3) Difficult * $\ldots \ldots \ldots \ldots \ldots \ldots$. $: 5.1$

Punishment was administered by grills connected with a calibrated inductorium. It was found that the number of trials necessary to form the habit of choosing the darker of the two screens when the difference in illumination is great decreases with the stimulus. This law holds, for discriminations of medium difficulty, only for the lower intensities of the stimulus. It holds likewise for difficult discriminations if the records of the chicks which succeeded in making it are alone considered. "If, however, we consider only the chicks which fail, the optimal stimulus recedes once more to a point nearer the threshold of stimulation than in the case of medium discrimination."

In the present state of the subject it is very doubtful if such results can be wholly relied upon. Quantitative experiments designed to isolate the effect of punishment are full of pitfalls. The effect is masked by practice effects, individual variation in animals, variations from day to day in the same animal, and by the almost insuperable difficulty of keeping an inductorium running for long periods of time without introducing serious errors due to the oxidation of the contacts through sparking, heating, etc. No condenser was connected across the terminals. Apart from the difficulties inherent in the method, Cole certainly worked with extreme care. The only criticism which can be 
urged in the conduct of the work was the failure to carry out control tests without punishment in each of the three sets of experiments.

Mammals. Hamilton's (I I) paper voices a protest against the detailed and narrow experimental studies in behavior. His interest is not centered in the acquisition of definite habits, but rather in the reaction tendencies displayed by the animal when face to face with a situation for which it has no appropriate instinct, no opportunity for imitation, and no rational equipment. He states his problem as follows: "What, if any, are the qualitative differences of reaction tendency that account for the fact that some mammals learn slowly, and with many errors, to meet situations which their fellows of superior age or race learn to meet quickly and with few errors?" In order to gain insight into the different reaction tendencies of his subjects, he gives them a problem in which it is required to obtain exit from a room containing five doors. One of the doors is for entrance only. Each of the remaining four doors may give exit but only one gives exit in any given trial. The subject has to find which door gires exit. He must push against it: if he finds it locked he must try another. It will be seen at once that the type of problem is quite new.

The subjects chosen were human beings, monkeys, dogs, cats and horses, of different ages. From the varying beharior of these subjects he succeeds in isolating what he calls various types of reaction:

Type A: "The reaction must include a single, definite effort to open each of the three inferentially possible doors, and must not include an effort to open the inferentially impossible door." (The impossible door varied from trial to trial). This is the rational inference type: apparent only in the eight normal adult subjects.

Type B: This reaction involves trying all four doors but once each and in an irregular order: The unmodified searching tendency. It is exhibited by one defective and by all of the animals in the following order with respect to frequency of its display: monkeys, dogs, cats, horses.

Type C: Striking once, each of the four doors in succession, starting either left or right. (This can occur only when either door I or door 4 is locked). The tendency to adopt stereotyped modes of searching: especially exhibited by monkeys. 
Type D: This involves the error of making more than one separate continuous effort to open a given door during the same trial, but always with an interruption of such repetitions of activity by an interval of effort to open one or more of the other doors. The searching tendency modified by recrudescent motor impulses: regularly increases as we descend the phyletic scale.

Type E: Includes several different modes of behavior which have a common objective characteristic, vi.., automatism. This is a relatively implastic and unadaptive mode of behavior. The tendency towards perseveration of active impulses and inhibitions: increases regularly when both phylogenetic and ontogenetic scales are descended.

Bogardus and Henke (3) studied in the rat the rôle played by head and nose contact in lcarning the maze. The vibrissae were cut off before experimentation began in order to facilitate the observation of the actual head and nose contacts made at the corners of the maze. It was found that the percentage of corners touched is high at first, and then gradually decreases as the maze is learned. There is a high correlation between the number of contacts and the number of errors made, and between the increase and decrease of time and the number of contacts. When the maze is learned, contact at corners is no longer necessary. Blind rats (previously trained on another maze) were then required to learn the maze used in the first set of experiments. The results obtained were similar to the above, and add weight to the contact theory of acquiring kinaesthetic and organic cues. This general conclusion is further strengthened by experiments in which the pathways of the maze were altered in various ways.

Hicks (I 4 ) gives a timely and exceedingly valuable discussion of the relative values of the different curves of learning. The author holds that the distance curve is a better representative of the progress towards automatic accuracy than the error curve. It, however, is impracticable from the standpoint of recording and manipulating the data. The prevalent practice of omitting all total and partial returns from the error record, and of making no attempt to evaluate varying degrees of error, gives a curve which is not only worthless but false. It is suggested that an error curve which includes returns, and which is constructed on 
the basis of regarding a small segment of the maze as the unit of error, constitutes a practicable substitute for the excellencies of the total distance curve. Time is the best single criterion.

\section{REFERENCES}

1. Bauer, V. Zu meinen Versuchen über das Farbenunterscheidungsvermögen der Fische. Erwiderung an C Hess. Arch. f. d. ges. Physiol., 137, 622-627.

2. Baver, V. Ueber das Verhalten des Sehpurpurs beim Tagessehen. Arch. i. d. ges. Physiol, 141, 479-496.

3. Bogardus, E. S. and Henke, F. G. Experiments on Tactual Sensations in the White Rat. Jour. Animal Behav., 1, 125-137.

4. Brefed, F. S. The Development of Certain Instincts and Habits in Chicks. Behavior Monographs, 1 , no. 1.

5. Casteel, D. B The Discriminative Ability of the Painted Turtle. Jour. Animal Behav., 1, 1-29.

6. Chappeluier, M. Indifférence sexuelle chez les femelles de Fringillidés hybrudes. Bull. Inst gén psych, 1911, 500-501.

7. Cole, L. W. 'The Relation of the Strength of the Stimulus to Rate of Learning in the Chick. Jour. Animal Behav., 1, 111-125.

8. Cralg, W. The Expression of Emotions in Pigeons. II. The Mourning Dove (Zenaidura macroura Linn). The Auk, 28,398-407.

9. Craig, W. III. The Passenger Pigeon (Ectopistes migratorius). The Auk, $28,407-427$.

10. Craig, W. Oviposition Induced by the Male in Pigeons. Jour. Morph., 22, $299-303$.

11. Hamlion, G. V. A Study of Trial and Error Reactions in Mammals. Jour. Animal Behav, 1, 33-67.

12. Herrick, F. H. Nests and Nest-building in Birds. Jour. Animal Behav., $1,159-193,244-278,336-374$.

13. Hess, C. Experimentelle Untersuchungen zur vergleichenden Physiologie des. Gesichtssinnes. Arch. \%. d ges. Physiol., 142, 405-446.

14. Hicks, V. C. The Relative Value of the Different Curves of Learning. Jour. Animal Behav., 1, 138-156.

15. Hunter, W. S. Some Labyrinth Habits of the Domestic Pigeon. Jour. Animal Behav., 1, 278-305.

16. MÁDAY, V. Das Orientierungsvermogen des Pferdes. Zett. angew. Psychol., $5,54-87$.

17. Minkowsin, M Zur Physiologie der Sehsphare. Arch. f. d. ges Physiol., 141, 171-327.

18. Mulder, W. Analysis of the Rotation Reflex in the Frog. Quart Jour. Exper. Physiol., 4, 231-235.

19. Parker, G. H. The Olfactory Reactions of the Common Killifish, Fundulus heteroclitus Linn. Jour. Exper. Zool., 10, 1-7.

20. Parker, ( $\mathrm{x}$ H. Effects of Explosive Sounds such as Those Produced by .Motor Boats and Guns upon Fishes. Bureau of Fisheries, Document no. 752.

21. Rouvis, B. Zur Frage der Schlafstellungen der Fische. Biol. Cent., 31, 183-185.

22. Schatefrer, A A. Habit Formation in Frogs. Jour. Animal Behav., 1, 309335.

23. Shampon, R. E. The Sense of Smell in Selachians. Jour. Exper. Zool., 10, 51-63.

24. Shephend, W. T. The Discrmination of Articulate Sounds by Raccoons. Amer. Jour. Psychol., 22, 116-119

25. Shepherd, W. T. Imitation in Raccoons. Ibid., 583-585.

26. Strong, R. M. On the Olfactory Organs and the Sense of Smell in Birds. Jour. Morph., 22, 619-662.

27. Sumner, F. B. The Adjustment of Flatfish to Various Backgrounds. Jour. Exper. Zool., 10, 409-507.

28. Werner, F. Oeber die Schlafstellungen des Fische. Biol. Cent, 31, 41-44. 